\title{
INTERNAUTA BRASILEIRO: PERFIL DIFERENCIADO, OPINIÕES INDIFERENCIADAS
}

\author{
Rogerio Schlegel ${ }^{1}$
}

\section{RESUMO}

O artigo pretende contribuir para melhorar a compreensão das relações entre o uso da internet, de um lado, e a participação política dos cidadãos, de outro. Sua ênfase é nos fatores que determinam o uso regular da internet e no perfil do internauta em termos de participação e valores relacionados à política. A análise dos dados do survey Latinobarómetro de 2007 aponta a idade e a escolaridade como principais determinantes do uso da internet no Brasil, sendo que a ocupação e uma proxy para renda não tiveram impacto consistente na chance de conectar-se, contrastando com os casos de Argentina e Chile. Ao mesmo tempo, o público que integra a comunidade on-line mostrou maior mobilização, em termos de participação política tradicional, e pouca diferenciação em matéria de opiniões sobre política, na comparação com os não-usuários da nova tecnologia. Essas evidências sugerem que a conexão ao mundo digital tende a dar voz a segmentos que já contam com acesso privilegiado a governantes e elaboradores de políticas, sobretudo por seu capital cultural, embora haja sinais da existência de oportunidades para outros setores sociais. Também indicam que a importância do "digital divide" no país deve ser relativizada, uma vez que os internautas não apresentam opiniões com orientação claramente destoante do restante da população.

PALAVRAS-CHAVE: internet; participação on-line; democracia; confiança política.

\section{INTRODUÇÃO}

O estudo do impacto da internet na política brasileira até aqui tem enfatizado os usos e o potencial de interação por meio de portais de governos, as casas do poder Legislativo e as campanhas eleitorais. Embora de elevada relevância, essa abordagem tem feito que outras dinâmicas geradas pelas novas tecnologias sigam como um campo ainda pouco explorado pela pesquisa brasileira. $\mathrm{O}$ espectro de conseqüências possíveis para a expansão do universo digital é amplo: redução dos custos de acesso à informação, pluralização das fontes disponíveis, superação dos fluxos de comunicação unidirecionais, enfraquecimento do poder dos gatekeepers tradicionais, prolongamento das redes de mobilização para além de fronteiras nacionais, possibilidade de deliberação e tomada de decisão em massa e em tempo real. Da promoção de novos valores ao florescimento da democracia direta, os processos políticos passíveis de influência parecem ilimitados.

1 Gostaria de agradecer a contribuição dos pareceristas anônimos da RSP, cujas observações contribuíram para aprimorar a elaboração teórica deste trabalho. Além disso, agradeço ao Nuffield College, da Universidade de Oxford, pelo acesso aos dados do Latinobarómetro".
Este artigo pretende contribuir para melhorar a compreensão das relações entre o uso da internet, de um lado, e a participação política dos cidadãos, de outro. Sua ênfase é nos fatores que determinam o uso regular da internet e o perfil do internauta em termos de participação e valores relacionados à política. Diante das possibilidades de ampliação da participação que as novas tecnologias representam, nosso estudo tem caráter exploratório e trabalha duas questões de fundo: os determinantes do acesso regular à internet atuam apenas para reforçar a inclusão dos que já estão politicamente incluídos - como os mais escolarizados, os mais ricos ou os mais mobilizados - e assim vê-se frustrada a chance de dar voz a setores com menos acesso a políticas públicas e policy-makers? E as opiniões dos internautas são atualmente representativas do conjunto da população ou, ao contrário, revelam vieses capazes de gerar distorções em políticas e deliberações públicas caso sejam tomadas como voz da maioria?

As evidências obtidas neste trabalho, a partir da análise estatística de dados de uma onda do survey Latinobarómetro, sugerem que o universo virtual tende a reforçar o poder de quem já tem poder sobretudo os detentores de capital cultural diferenciado. Mas essa afirmação abrangente tem de vir 
acompanhada de ressalvas. A comunidade digital é capaz de atrair segmentos não usualmente associados à participação política tradicional. Em linha com resultados internacionais, os mais jovens apareceram sobre-representados nessa comunidade ${ }^{2}$, um traço promissor caso essa presença converta-se em envolvimento com a política. Além disso, características sócio-demográficas que em outros contextos revelaram-se decisivas para reforçar a exclusão on-line de segmentos já com deficit de poder não se mostraram efetivas no caso brasileiro etnia, ocupação, gênero e uma proxy para renda ${ }^{3}$ não afetaram as chances de conectar-se de forma regular à rede mundial de computadores.

$\mathrm{Na}$ tentativa de localizar o caso brasileiro no mapa global do uso de internet, foi feita análise comparativa com a Argentina e o Chile, usando dados da onda 2007 do Latinobarómetro. Tratase de dois países selecionados por suas semelhanças com o Brasil do ponto de vista da trajetória histórica, ao mesmo tempo em que apresentam diferenças marcantes em termos de uso da World Wide Web; em matéria de acesso, ambos estão mais próximos da Europa do que do Brasil ou da América Latina. A comparação permitiu explorar em alguma medida a hipótese da normalização, segundo a qual distorções no acesso à internet relacionadas a características sócio-demográficas tendem a desaparecer à medida que o uso da nova tecnologia difunda-se para toda a sociedade (NORRIS, 2001) ${ }^{4}$. As evidências encontradas contrariam essa hipótese.

No que se refere ao perfil da comunidade online, também emergiram sinais de que conclusões sobre países de democracia mais antiga e maior

2 Em diferentes países, acesso e uso são proporcionalmente maiores nos segmentos mais jovens, embora haja usuários em todas as faixas etárias (COLE et alii, 2003; LLOYD \& BILL, 2004; LIVINGSTONE, COULDRY \& MARKHAM, 2007).

3 Trata-se de uma variável que presumivelmente tem forte correlação com a variável cuja utilização seria desejável no caso, a renda - e que é incluída na análise como medida aproximada dela.

4 O conceito de "normalização" tem sido utilizado com duas acepções diferentes na pesquisa sobre internet. Norris (2001, p. 30-31) emprega-o com um sentido próximo ao de saturação: à medida que a nova tecnologia difunde-se pela sociedade, por conta de queda no preço e maior facilidade de operação, grupos sociais inicialmente excluídos do uso passariam a ter acesso, no limite equalizando os diferentes desenvolvimento econômico não podem ser simplesmente transpostas para a realidade brasileira ou sul-americana. O internauta brasileiro hoje não demonstra de forma consistente valores diferentes do restante da população. Não há sinais robustos da inclinação liberal na economia, de maior apoio à democracia ou de maior confiança nas instituições, detectados em parte dos estudos internacionais.

De forma geral, são achados que justificam visão menos pessimista sobre a forma como a nova tecnologia tem se expandido no Brasil, embora os dados revelem que fundamentalmente a internet tem favorecido os setores com posição mais central na política e na sociedade. A internet hoje contribui para incluir quem já está incluído, mas há sinais de oportunidades para outros setores sociais.

Nas seções a seguir, revejo conceitos que contribuem para a compreensão das dimensões políticas do uso da internet, formulo as proposições que serviram como hipóteses de trabalho e procedo à análise estatística dos dados do Latinobarómetro. Por último, apresento interpretações para as evidências encontradas e aponto como estas podem ajudar a compreender parte das relações entre internet e política no Brasil contemporâneo.

\section{INTERNET E DEMOCRACIA}

A interpretação sobre o sentido das mudanças que a internet $\mathrm{e}$ as tecnologias digitais representam divide pesquisadores e ensaístas. Dentro dos limites deste artigo, é desnecessário revisar em detalhes as concepções conflitantes para o futuro da política e da sociedade, já sintetizadas em termos de abordagens ciber-otimistas, ciber-pessimistas e ciber-céticas (v. NORRIS, 2001). Mas, com a difusão em escala mundial da World Wide $W e b$, rumando para a saturação nas nações pioneiras e ampliando em saltos sua penetração em países em desenvolvimento (como Brasil, Argentina e Chile), torna-se cada vez mais viável avaliar empiricamente em que direção caminha a influência das tecnologias digitais no campo político.

segmentos - a exemplo do que ocorreu com o automóvel, a TV e o telefone. Para Margolis e Resnik (2000, p. 2), a hipótese da normalização consiste na presunção de que, à medida que a internet desenvolve-se ela reproduz padrões de relações socioeconômicas e políticas existentes no mundo off-line. Neste artigo, emprego o termo com o primeiro sentido. 
A participação é uma esfera privilegiada para a observação desses impactos: trata-se do mecanismo central do funcionamento democrático. Em sentido mais amplo, a participação dos cidadãos é a base para o autogoverno que diferencia a democracia de outros regimes políticos. O voto é a forma decisiva de tomar parte nos destinos da polity, mas há outros mecanismos que permitem ao indivíduo controlar as decisões coletivas que afetam sua vida, como os grupos de pressão, de associações voluntárias e os processos relacionados às dinâmicas de opinião pública que informam e contribuem para a accountability dos policymakers (DAHL, 1989; PAGE \& SHAPIRO, 1992; VERBA, SCHLOZMAN \& BRADY, 1995).

Normativamente, é desejável que as decisões coletivas considerem igualitariamente as preferências de cada cidadão. No caso do voto, esse princípio é expresso pela máxima "um homem, um voto" e traduzido pela inclusão eleitoral ampla, que ao menos formalmente visa a garantir a igualdade como fundamento da escolha democrática. No caso do debate público, operam processos mais complexos, descritos por esquemas teóricos com diferentes ênfases: em termos de competição intraelites (SCHUMPETER, 1984; DOWNS, 1999), especialização e foco em temas (DAHL, 1989; CONVERSE, 2006), divisão de trabalho entre segmentos do público (NEUMAN, 1986) e racionalização e deliberação coletiva (PAGE \& SHAPIRO, 1992; HABERMAS, 2003), por exemplo. Ainda que a maneira pela qual esses processos sejam entendidos teoricamente seja controversa, é consistente a associação constatada entre preferências individuais e políticas públicas adotadas por governantes, ao menos em países como os Estados Unidos e o Reino Unido (PAGE \& SHAPIRO, 1992; DELLI CARPINI \& KEETER, 1997; WLEZIEN \& SOROKA, 2007).

As necessidades e reivindicações dos grupos com mais condições de fazer chegar suas preferências ao sistema político tendem a ser mais acolhidas pelos mecanismos que processam esses inputs. Assim, a participação pelo voto (ou em campanhas), por meios não-eleitorais (em demonstrações públicas, abaixo-assinados, contato direto com governantes, participação em grupos de pressão etc.) e a expressão de demandas pela mídia tradicional são exemplos de canais para direcionar a atenção dos policy-makers para as preferências dos cidadãos, e assim levar ao seu atendimento por políticas públicas. Na medida em que a participação aumenta a chance de acolhimento de demandas, a não-participação opera no sentido inverso, distanciando do sistema político quem não dispõe de canais ou quem não expressa suas preferências. Não à toa, a participação desigual já foi descrita como persistente "dilema democrático não-resolvido" (LIJPHART, 1997).

Outro fator que torna a observação da participação especialmente relevante é o grande impacto esperado, nessa dimensão da política, por conta do avanço das novas tecnologias. A expansão da internet, seja em termos de acesso do público, seja em termos da atenção dedicada pelos policymakers, renova a forma como a questão da participação coloca-se. Esse novo canal de expressão de preferências concorre com a mídia tradicional em matéria de transferir inputs para o sistema político. Em si, isso já representaria a abertura de uma nova frente para atuação na vida política. Mas as tecnologias digitais oferecem possibilidades ainda mais amplas e antes não imaginadas para os meios de comunicação, a exemplo da comunicação interativa e multidirecional, da capacidade de conexão instantânea, da erradicação das noções de distâncias e da oferta abundante de informação a custo baixo (BARBER, 1998; 2004). Torna possível, por exemplo, consultar a comunidade sobre determinada pendência em espaço curtíssimo de tempo ou mobilizar pessoas que não se conhecem em diferentes cantos do mundo.

A tecnologia digital também é descrita como tendo potencial para ampliar o engajamento do cidadão na vida política. O modelo de participação proposto por Verba, Schlozman e Brady (1995) é especialmente útil para a compreensão desse ponto. Ele dá centralidade à motivação do indivíduo e aos custos com que tem de arcar para influenciar nas decisões públicas. De forma geral, os custos de participar são desproporcionalmente altos em relação aos benefícios, quando estes são tomados apenas em termos de ganhos materiais individuais. Mas não há paradoxo em participar, sustentam os autores, pois há outras motivações e recompensas envolvidas, relacionadas ao mundo dos valores - a satisfação de demonstrar solidariedade, por exemplo. Ainda assim, os custos são capazes de limitar a participação; mesmo pessoas potencialmente interessadas necessitam de dinheiro, tempo, habilidades cívicas e conexões com redes de mobilização para superar os obstá- 
culos iniciais. Isso ajuda a explicar por que, em décadas de investigação empírica, é mais provável que os cidadãos com melhor situação econômica e maior centralidade social participem mais - seus custos para tentar influenciar os governantes são menores em termos relativos, por conta de estoques menos limitados de recursos pessoais.

Nessa equação, a internet pode afetar tanto o fator motivação quanto o fator custos. É plausível pensar o internauta como tendo valores característicos, consolidados por efeito de seleção: a nova tecnologia atrai pessoas que tendem a ter perfil recorrente ou valores comuns; ou desenvolvidos no próprio universo virtual: alguém menos atento a determinado assunto pode desenvolver novas inclinações após participar, por exemplo, de chats envolvendo grupos de interesse. Se a internet vê de fato florescer uma 'cibercultura' com traços pós-materialistas, privilegiando a autoexpressão, as relações não-hierárquicas e a democracia participativa, pode-se esperar que esses valores favoreçam a motivação para participar. E, em matéria de custos, as tecnologias digitais reduzem drasticamente os recursos necessários na busca de informações e na comunicação, facilitando a organização de movimentos e entidades, a mobilização de ativistas e o contato com policymakers ou intermediários, como líderes partidários e jornalistas. Os ganhos de produtividade também representam um ganho de tempo (DELLI CARPINI, 2000) - embora muitos adolescentes sejam testemunhas de que o próprio mundo virtual oferece mil atrativos e formas para gastar o tempo extra.

Dados do survey Eurobarômetro indicaram que, na virada da década passada, os internautas europeus eram mais participativos em termos de ações tradicionais, como discutir política, tentar persuadir conhecidos e votar nas eleições para a União Européia. Também tinham maior conhecimento sobre assuntos políticos e expunham-se mais ao noticiário de jornais e rádio - não ao de TV. Os mais jovens, os mais ricos, os mais escolarizados, os homens e os ocupantes de postos gerenciais eram proporcionalmente sobre-representados nas comunidades virtuais européias. Em termos de valores, os internautas tendiam à agenda pós-materialista, prezando a democracia participativa e o cosmopolitismo mais do que os não-conectados. E também tinham maior confiança nas instituições, inclusive governos nacionais e parlamentos

\section{(NORRIS, 2001).}

Na revisão dos marcos teóricos relevantes para esta discussão, resta salientar diferenças entre as formas tradicionais de participação e a participação on-line. Nos Estados Unidos, algumas formas de participação pela internet já rivalizam com as formas tradicionais - há seis anos, era quase igual a proporção de cidadãos que entravam em contato com autoridades pela internet e a que utilizava meios como o correio e o telefone (CSRA, 2003). Já houve casos como o de Howard Dean, que surpreendentemente foi levado a liderar a disputa pela candidatura democrata à Presidência dos Estados Unidos em 2004 graças à mobilização via World Wide Web (LEVY, 2004).

Há sinais de que a participação on-line demande recursos diferentes da participação tradicional, operando em lógica que não permite a mera extrapolação das explicações teóricas da primeira para a segunda (KLING, 1999; BIMBER, 2000; KIESLER et alli, 2000). Best e Krueger (2005) encontraram evidências de que os fatores que predizem a participação on-line com freqüência são diferentes dos que influem na participação offline; as habilidades cívicas que favorecem a participação off-line podem não representar diferencial no mundo virtual, sendo necessárias competências específicas para a navegação na World Wide Web, por exemplo.

\section{II.1. Desigualdade digital}

Por tudo isso, as potencialidades ampliadas dos canais digitais agravam a preocupação com o chamado "digital divide" (NORRIS, 2001): a distância entre os que estão incluídos no universo digital e os que estão fora dele. Há temor de que a marginalização em relação ao mundo on-line possa produzir cidadãos de segunda classe, pessoas cuja condição de perdedor potencial seria aprofundada pela escassez de competências informacionais. Em princípio, os candidatos à marginalização ampliada são justamente os grupos que já apresentam déficits de poder no mundo pré-digital, a exemplo dos mais pobres, dos menos escolarizados, dos redundantes no mercado de trabalho. Sem acesso à internet $\mathrm{e}$ às novas tecnologias, correm o risco de se tornar invisíveis no mundo digital em que circulam governantes e policy-makers. Se essa tendência verificar-se, as novas tecnologias estarão contribuindo para ampliar a desigualdade social, reforçando a marginalização já presente em outras dimensões 
sócio-demográficas e econômicas. Além da ren$\mathrm{da}$, aparecem como fatores decisivos para a exclusão digital a escolaridade (desvantagem para os menos escolarizados), a ocupação (desvantagem para os trabalhadores manuais) e, em alguns países, a cor da pele (desvantagem para etnias discriminadas, como os negros nos Estados Unidos) e o gênero (desvantagem para as mulheres).

No que diz respeito especificamente à política, as novas tecnologias aprofundariam a diferença entre os que têm recursos e disposição para participar e os que não têm; com o agravante de que o grupo com mais recursos e o grupo com maior disposição tendem a sobrepor-se, pois ambos são compostos por indivíduos de melhor condição social. Pessoas com renda mais alta tendem a participar mais pelos caminhos tradicionais e também a ter mais acesso à internet. Vários estudos constataram a associação entre renda e acesso à internet em países com elevado nível de desenvolvimento econômico e humano (NTIA, 1999; OECD, 2000). E, ainda que os determinantes da participação on-line sejam diferentes dos da participação tradicional, os indivíduos de condição socioeconômica mais elevada tendem a contar com os dois conjuntos de características (BEST \& KRUEGER, 2005).

Contra essa tendência, há a hipótese da normalização defendida por 'ciber-otimistas'. Eliminar o fosso entre diferentes segmentos sociais em termos de uso da nova tecnologia seria apenas questão de tempo, pois a difusão crescente ten- deria a barateá-la e a tornar sua operação mais acessível. No limite, a internet tenderia à saturação, atingindo todos os segmentos sociais, a exemplo do que ocorreu em grande medida com o automóvel, a TV e o telefone. Norris (2001) não encontrou evidências que confirmassem essa hipótese para os países europeus na década de 1990. Os mais ricos tinham maior probabilidade de ter acesso no início do período e a distância manteve-se constante na segunda metade daquela década, apesar do crescimento próximo de $10 \%$ ao ano da população conectada na região. Mesmo nos países que poderiam ser considerados vanguarda na difusão da tecnologia, como Reino Unido, Dinamarca e Luxemburgo, o fosso não se fechou.

No Brasil, há sinais de haver grande associação entre posição social e acesso à internet. Pista disso é a distribuição do acesso segundo a escolaridade. No terceiro trimestre de 2008, o contraste entre as faixas de escolaridade seguia forte: no grupo com até o segundo grau completo, $45 \%$ usam a internet; esse índice sobe para $79 \%$ entre os que têm superior incompleto e atinge $92 \%$ para a faixa com superior completo ou pós-graduação (IBOPE, 2008) . Os homens revelavam-se mais envolvidos com a tecnologia, com $73 \%$ deles afirmando ter acesso, contra $64 \%$ entre as mulheres. $\mathrm{O}$ acesso era mais comum na residência $(45 \%)$ do que no local de trabalho $(30,8 \%)$ ou na escola $(31,9 \%)$. A idade aparecia como inversamente associada ao uso: no público entre 16 e 24 anos, $90 \%$ têm acesso; esse percentual cai a cada degrau etário, até chegar a $23 \%$ para as pessoas com mais de 65 anos.

GRÁFICO 1 - USUÁRIOS DE INTERNET NO BRASIL, NAARGENTINA E NO CHILE (EM MILHÕES)

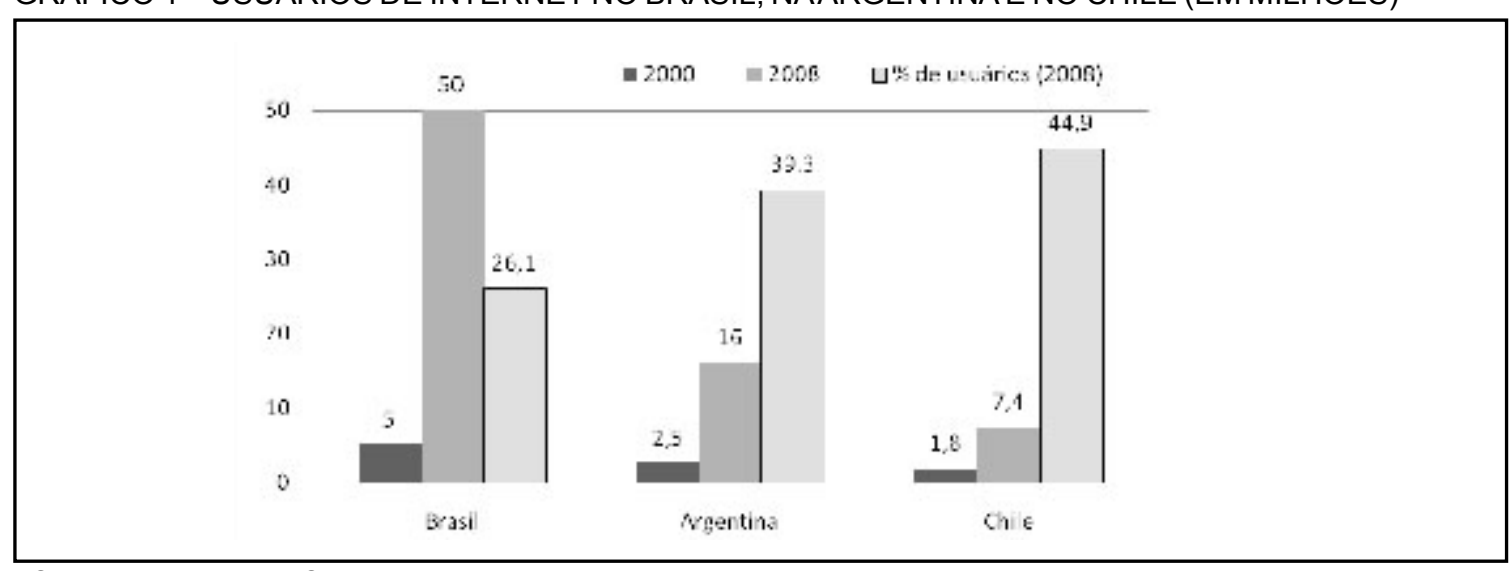

FONTE: Internet World Stats (2009).

NOTA: "Usuário" é considerado qualquer pessoa que cumpra dois requisitos: (1) ter acesso a um ponto de internet e (2) ter os conhecimentos básicos necessários para operar a tecnologia.

5 Os levantamentos do Ibope nessa área usam como universo de amostra o conjunto das pessoas com 16 ou anos

ou mais que possuem telefone. 
Em relação aos outros países considerados neste estudo, o Brasil tem os mais baixos percentuais de acesso à internet, apesar de ter apresentado o maior crescimento nesta década e de liderar em número absoluto de internautas (Gráfico 1). A taxa brasileira de acesso, pelos critérios do Internet World Stats, é de $26,1 \%$ - próxima da média latino-americana $(24,2 \%)$ e da média mundial $(21,9 \%)$. Argentina, com $39,3 \%$, e Chile, com $44,9 \%$, estão mais próximos da média européia $(48,5 \%)$.

A partir desses dados e da revisão teórica, esse estudo foi formatado para responder a duas perguntas de fundo: no Brasil, os fatores que determinam o acesso regular à World Wide Web atuam apenas para reforçar a inclusão dos que já estão politicamente incluídos, como os mais escolarizados ou de renda mais alta, que também tendem a participar mais por meios tradicionais? E as opiniões dos internautas são atualmente representativas do conjunto da população, ou produzem representações da polity com distorções que podem influenciar o julgamento de governantes - por meio de enquetes on-line ou contato via $e$ mail, por exemplo? Para avançar no entendimento dessas questões, passamos à análise inferencial dos dados, contemplada na seção seguinte.

\section{ANÁLISE DOS DADOS}

Para avaliar os determinantes do acesso à internet no Brasil e o perfil do internauta em termos de participação tradicional e atitudes políticas, apresentando perspectiva comparada com Argentina e Chile, foram usados dados do survey Latinobarómetro, onda de 2007, com as características descritas no Quadro $1^{6}$.

QUADRO 1 - CARACTERÍSTICAS NACIONAIS DO LATINOBARÓMETRO 2007 - BRASIL, ARGENTINA E CHILE

\begin{tabular}{|c|c|c|c|c|c|}
\hline & Instituto & Amostragem & $\mathbf{N}$ & $\begin{array}{l}\text { Margem } \\
\text { de erro }\end{array}$ & $\begin{array}{c}\text { Representati- } \\
\text { vidade }\end{array}$ \\
\hline Brasil & Ibope & $\begin{array}{l}\text { Probabilística modificada, } \\
\text { probabilística em } 3 \text { etapas e } \\
\text { por cotas na etapa final }\end{array}$ & 1.204 & $2,8 \%$ & $\begin{array}{l}100 \% \text { da } \\
\text { populaçẫo }\end{array}$ \\
\hline Argentina & $\begin{array}{l}\text { Equipes } \\
\text { Mori }\end{array}$ & $\begin{array}{l}\text { Probabilística modificada, } \\
\text { probabilística em } 3 \text { etapas e } \\
\text { por cotas na etapa final }\end{array}$ & 1.200 & $2,7 \%$ & $\begin{array}{l}100 \% \text { da } \\
\text { populaçẫo }\end{array}$ \\
\hline Chile & $\begin{array}{l}\text { Mori } \\
\text { Chile }\end{array}$ & Probabilística em 3 etapas & 1.200 & $2,8 \%$ & $\begin{array}{l}100 \% \text { da } \\
\text { populaçẫo }\end{array}$ \\
\hline
\end{tabular}

FONTE: Latinobarómetro (2007)

Os surveys Latinobarómetro são desenhados para avaliar atitudes e valores políticos de cidadãos de 18 países latino-americanos, sem preocupação especial com o impacto das novas tecnologias. A partir de 2000 (e com a exceção de 2004), foram incluídas nos questionários perguntas sobre a World Wide Web, em geral questionando se o entrevistado costuma acessar a internet $\mathrm{e}$ qual o tipo de uso mais freqüente quando acessa.

O trabalho com análise secundária de dados impõe limitações. Seria especialmente desejável

\footnotetext{
6 A base de dados inclui 18 países latino-americanos e está disponível para download no sítio da corporação Latinobarómetro (Cf. LATINOBARÓMETRO, 2009),
} com custo fixado em 100 euros. avaliar a participação on-line, mas o questionário utilizado pelo Latinobarómetro não contemplou esse tipo de conteúdo em nenhuma onda anual. No caso da renda, foi utilizada uma proxy, pois em 2007 não havia pergunta direta sobre rendimentos individuais ou familiares do entrevistado ${ }^{7}$. Em matéria de valores, o desenho ideal de pesqui-

\footnotetext{
7 O entrevistado foi convidado a imaginar uma escada com dez degraus, em que o primeiro degrau conteria o mais pobre e o décimo, o mais rico. Em seguida, foi instado a localizar-se em um dos degraus. Após observação da distribuição de freqüências, foi construída a variável utilizada nas análises seguintes, atribuindo-se renda baixa aos que se localizaram até o degrau quatro, renda média para os que se localizaram no degrau cinco e renda alta para os que se localizaram em degraus mais elevados.
} 
sa envolveria baterias de perguntas que permitissem construir índices, de forma a aumentar a consistência com que a posição do respondente é localizada; no entanto, o questionário aplicado em 2007 não tinha esse objetivo expresso e para algumas dimensões só oferece perguntas isoladas.

Levando em conta limitações como essas, foram consolidadas quatro proposições principais, tomadas como hipóteses de trabalho: (1) no Brasil, escolaridade, renda e ocupação são determinantes consistentes do acesso regular à internet, reproduzindo o padrão de países economicamente desenvolvidos; (2) o internauta brasileiro apresenta níveis de participação tradicional mais elevados do que o restante da população, reproduzindo o padrão de países desenvolvidos; (3) o internauta brasileiro apresenta valores ligados à política diferenciados do restante da população, reproduzindo o padrão de países desenvolvidos: espera-se que apóie mais a democracia, que tenha maior confiança nas instituições, que seja mais liberal e menos estatista em matéria de eco- nomia, que defenda pontos de vista mais igualitários em termos sociais e que seja mais tolerante nos julgamentos morais; (4) Argentina e Chile apresentam menor diferenciação entre usuários e nãousuários da internet, se comparados ao Brasil, por conta da normalização decorrente da maior difusão proporcional da nova tecnologia nessas duas sociedades. A hipótese estará tanto mais perto de ser confirmada à medida que as variáveis sóciodemográficas mostrarem-se ineficazes como determinantes do uso da internet, num sinal de equalização do acesso.

\section{III.1. Determinantes do acesso}

O primeiro passo da análise foi identificar fatores sócio-demográficos, políticos e relacionados ao uso da mídia tradicional que podem favorecer o acesso à World Wide Web. Foi utilizada como variável dependente o uso regular da internet ${ }^{8}$, entendido como acesso diário ou ocasional, que apresentou as freqüências descritas no Quadro $2^{9}$.

QUADRO 2 - USO REGULAR DA INTERNET (FREQÜÊNCIAS, EM \%) - BRASIL, ARGENTINA E CHILE

\begin{tabular}{|l|c|c|c|}
\hline & Brasil & Argentina & Chile \\
\hline Usa diariamente ou ocasionalmente & 32,9 & 43,3 & 33,9 \\
Nunca usou ou quase nunca usa & 67,1 & 56,7 & 66,1 \\
\hline
\end{tabular}

FONTE: Latinobarómetro (2007).

$\mathrm{Na}$ análise inferencial, foram utilizadas regressões logísticas múltiplas, modalidade mais ade-

\footnotetext{
8 A pergunta utilizada pelo Latinobarómetro 2007 foi a seguinte: "Alguma vez em sua vida o sr. usou correio eletrônico ou se conectou à internet?". E as respostas: "Sim, todos os dias"; "Sim, ocasionalmente"; "Sim, quase nunca" e "Não, nunca" (tradução do autor a partir do questionário em espanhol).

9 Para o Chile, a proporção de usuário apresentou discrepância em relação aos dados do Internet World Stats, enquanto Brasil e Argentina estão em patamares compatíveis com aqueles números. Isso se explica pela maneira diversa com que as duas fontes obtiveram o indicador: o Latinobarómetro pretende representar $100 \%$ da população do país, mas usa variáveis sócio-demográficas para estratificar a amostra; o Internet World Stats trabalha com amostragem destinada a apurar mais precisamente a parcela de usuários da internet. A discrepância precisa ser levada em consideração na interpretação dos dados, pois no caso do Chile o teste da hipótese de normalização pode acabar prejudicado.
}

quada para tratar uma variável dependente que se apresenta como binária ( 0 ou 1$)$, como a descrita acima $^{10}$. Para cada país, foram construídos três

10 O procedimento estatístico permite avaliar o impacto de cada variável independente considerando sua atuação conjunta com as demais, isto é, equivale a controlar todas as variáveis incluídas no modelo ao mesmo tempo (HOSMER \& LAMESHOW, 2000; LATORRE, 2004; PERES, OLIVEIRA \& ANOROZO, 2008). Aqui os resultados foram expressos em razões de chance (em inglês, odds ratio) e espelham a direção e a intensidade com que alterações na variável dependente influenciam a variável independente. Valores acima de um indicam que um aumento na variável independente produz um aumento na variável dependente, portanto, trata-se de um fator que favorece o resultado definido como sucesso - no caso, o uso regular da internet. Valores abaixo de um indicam diminuição na variável dependente quando há aumento da independente, resultado que aponta um fator de proteção ou desfavorecimento. Razão de chance igual a um sugere que a variável independente não tem impacto na dependente, da 
modelos de regressão. O primeiro tem apenas quesitos sócio-demográficos como variáveis independentes; o segundo inclui variáveis políticas (interesse declarado pela política e participação em entidades e associações secundárias) e o terceiro abrange o uso da mídia tradicional, isto é, exposição intensiva (mais de 5 vezes por semana) a noticiários de $\mathrm{TV}$, jornal ou rádio.

Os modelos para o caso brasileiro (Quadro 3) apontaram a consistência da escolaridade como determinante do acesso à internet. Nos três casos, as variáveis relativas à educação formal tiveram significância e com razões de chance elevadas. No primeiro modelo, a chance de alguém com superior incompleto ou mais escolaridade ter acesso regular foi 63,6 vezes a de alguém que tem primário incompleto - a categoria de referência para essa variável - mesmo com o controle das outras variáveis sócio-demográficas ${ }^{11}$.

A idade, como era de se esperar, também se mostrou um determinante robusto em todos os modelos. A chance de acessar a internet diminui com os anos de vida do entrevistado: todas as faixas etárias que aparecem no Quadro tiveram razão de chance menor do que 1 , o que indica que são fator de desfavorecimento se comparadas à categoria de referência (idade de 16 a 25 anos). Uma pessoa com mais de 55 anos tem $0,081 \mathrm{vez}$ a chance de um jovem de 16 a 25 anos de conectarse; calculando inversamente, o grupo mais jovem tem 12,3 vezes a chance do mais velho, controladas as demais variáveis.

Uma variável relacionada ao local de moradia revelou influência consistente nos três modelos. Pessoas que moram em grandes centros, com mais de 100 mil habitantes, têm maior chance de serem usuárias da internet do que quem mora em municípios menores.

Renda, ocupação, gênero e etnia não mostraram influência para determinar o acesso à internet. No quadro, suas razões de chance e valores de $p$ não aparecem em negrito, pois não tiveram significância estatística e não foi possível rejeitar a hipótese nula - ou seja, pode não haver associação entre essas variáveis e a variável dependente. O resultado para a renda é especialmente surpreendente, sem significância em todos os modelos. É preciso relembrar que se trata de uma proxy; no entanto, a variável teve significância nos casos de Argentina e Chile, como se verá adiante.

QUADRO 3 - REGRESSÃO LOGÍSTICA - BRASIL - USO REGULAR DA INTERNET

\begin{tabular}{|c|c|c|c|c|c|c|}
\hline & \multicolumn{2}{|c|}{$\begin{array}{l}\text { Modelo } 1 \\
\text { (só sócio- } \\
\text { demográficas) }\end{array}$} & \multicolumn{2}{|c|}{$\begin{array}{c}\text { Modelo } 2 \\
\text { (com variáveis } \\
\text { políticas) }\end{array}$} & \multicolumn{2}{|c|}{$\begin{array}{l}\text { Modelo } 3 \\
\text { (com mídia } \\
\text { tradicional) }\end{array}$} \\
\hline & $\begin{array}{c}\text { Razẫo de } \\
\text { chance }\end{array}$ & $p$ & $\begin{array}{l}\text { Razẫo de } \\
\text { chance }\end{array}$ & $p$ & $\begin{array}{l}\text { Razẫo de } \\
\text { chance }\end{array}$ & $p$ \\
\hline \multicolumn{7}{|l|}{ Idade (ref.: de 16 a 25 anos) } \\
\hline De 26 a 35 & 0,355 & 0,000 & 0,344 & 0,000 & 0,356 & 0,000 \\
\hline De 36 a 45 & 0,268 & 0,000 & 0,256 & 0,000 & 0,217 & 0,000 \\
\hline De 46 a 55 & 0,199 & 0,000 & 0,180 & 0,000 & $\mathbf{0 , 1 8 1}$ & 0,000 \\
\hline Mais de 55 & 0,081 & 0,000 & 0,069 & 0,000 & 0,072 & 0,000 \\
\hline Mulher & 0,790 & 0,177 & 0,922 & 0,659 & 1,004 & 0,985 \\
\hline
\end{tabular}

forma como se apresenta no modelo de regressão. A significância de cada fator foi apurada usando o teste de Wald e representa a possibilidade de que não haja associação (ou variação coordenada) entre a variável independente e a variável dependente - isto é, representa a probabilidade de rejeitar a hipótese nula. Arbitrariamente, foi definido o patamar de $95 \%$ de probabilidade $(\mathrm{p}<=0,05)$ como limiar para rejeitar a hipótese nula.

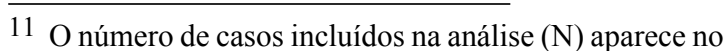
rodapé dos quadros a seguir e é menor do que a amostra total porque os casos em que não havia informação para uma das variáveis consideradas (missing) foram excluídos do teste. Também estão no rodapé o $\mathrm{r}^{2}$ de Negelkerke, que pode ser tomado como indicador da proporção da variação da variável dependente explicada em cada modelo, e o teste de Hosmer e Lemeshow, para verificar a adequação do modelo para prever os casos de sucesso $(\mathrm{y}=1)$. 


\begin{tabular}{|c|c|c|c|c|c|c|}
\hline Escolaridade (ref. $1^{\text {sio }}$ inc.) & & & & & & \\
\hline $1^{\text {ário }}$ completo & 3,672 & 0,000 & 3,626 & 0,000 & 4,730 & 0,000 \\
\hline $2^{\text {ŕio }}$ incompleto & 7,327 & 0,000 & 6,251 & 0,000 & 6,785 & 0,000 \\
\hline $2^{\text {ŕio }}$ completo & 11,453 & 0,000 & 10,126 & 0,000 & 9,889 & 0,000 \\
\hline Sup. incompleto ou mais & 63,560 & 0,000 & 48,807 & 0,000 & 65,312 & 0,000 \\
\hline \multicolumn{7}{|l|}{ Renda (ref. baixa) } \\
\hline Média & 1,353 & 0,133 & 1,408 & 0,096 & 1,370 & 0,169 \\
\hline Alta & 1,171 & 0,451 & 1,167 & 0,475 & 0,968 & 0,895 \\
\hline \multicolumn{7}{|l|}{ Ocupação (ref.: manuais) } \\
\hline Donos, liberais e gerenciais & 1,444 & 0,235 & 1,427 & 0,265 & 0,934 & 0,851 \\
\hline Estudantes & 1,806 & 0,107 & 1,626 & 0,191 & 2,388 & 0,057 \\
\hline Nẫo-PEA ${ }^{2}$ & 0,760 & 0,198 & 0,784 & 0,261 & 0,643 & 0,067 \\
\hline \multicolumn{7}{|l|}{$\begin{array}{l}\text { Etnia (ref.: negraimulatol } \\
\text { mestiç o) }\end{array}$} \\
\hline Branco & 1,198 & 0,305 & 1,220 & 0,270 & 1,087 & 0,679 \\
\hline Outros (inclui indígenas) & 0,852 & 0,675 & 0,866 & 0,716 & 0,939 & 0,880 \\
\hline \multicolumn{7}{|l|}{$\begin{array}{l}\text { Cidade (ref. até } 20 \text { mil } \\
\text { habitantes) }\end{array}$} \\
\hline Mais de 20 mil a 100 mil & 1,469 & 0,169 & 1,612 & 0,100 & 1,812 & 0,057 \\
\hline Mais de $100 \mathrm{mil}$ & 2,173 & 0,007 & 2,336 & 0,005 & 1,963 & 0,039 \\
\hline Interesse por política & & & 1,884 & 0,004 & 1,870 & 0,008 \\
\hline \multicolumn{7}{|l|}{ Associativismo } \\
\hline Partido & & & 1,175 & 0,552 & 1,216 & 0,504 \\
\hline Sindicato & & & 1,126 & 0,633 & 1,271 & 0,374 \\
\hline Igreja & & & 0,991 & 0,961 & 0,886 & 0,579 \\
\hline Grupo esportivolazeric ultura & & & 1,991 & 0,001 & 2,142 & 0,001 \\
\hline \multicolumn{7}{|l|}{ Mídia (5 ou + vezesisemana) } \\
\hline Vê notícias na TV & & & & & 1,168 & 0,446 \\
\hline Lê jornal & & & & & 1,861 & 0,033 \\
\hline Ouve notícias no rádio & & & & & 1,048 & 0,824 \\
\hline Constante & 0,163 & 0,000 & 0,106 & 0,000 & 0,094 & 0,000 \\
\hline \multirow[t]{2}{*}{$\mathbf{N}$} & & 1.166 & & 1.145 & & 966 \\
\hline & $\begin{array}{c}2 \text { Negelkerke } \\
\mathbf{0 , 5 3 8}\end{array}$ & $\begin{array}{c}\text { Teste de } \\
\text { H\&L } \\
0,612\end{array}$ & $\begin{array}{c}r^{2} \\
\text { Negelkerke } \\
0,569\end{array}$ & \begin{tabular}{|c} 
Teste de \\
H\&d \\
$\mathbf{0 , 2 3 4}$
\end{tabular} & $\begin{array}{c}r^{2} \\
\text { Negelkerke } \\
0,587\end{array}$ & \begin{tabular}{|c|} 
Teste de \\
H\&d \\
0,030
\end{tabular} \\
\hline
\end{tabular}

FONTE: Latinobarómetro (2007).

NOTAS: 1. Negrito destaca significância até $p<=0,05$.

2. PEA significa Pessoa Economicamente Ativa. 
Os resultados do modelo 2 indicaram que o interesse por política também é um determinante efetivo do acesso. Controladas as outras variáveis desse modelo, quem declarou muito ou algum interesse por política tem 1,884 vez a chance de conectar-se em relação a uma pessoa que se considera desinteressada. E, no modelo completo, a variável manteve sua significância. Pertencer ou ter pertencido a partido, sindicato ou igreja não foi determinante para o acesso. Tomar parte em associação esportiva, de lazer ou cultural, sim. É possível supor que no Brasil esse tipo de entidade tenda a disponibilizar pontos de acesso à World Wide Web, favorecendo o acesso - e o achado pode ser um indicativo relevante para informar políticas públicas e a ação de ONGs.

Por fim, no modelo 3, apenas a leitura freqüente de jornais mostrou-se determinante adicional para o uso regular da internet. É preciso observar que, por limitações na coleta de dados para as variáveis da mídia tradicional, $19,8 \%$ das observações entradas nesse modelo foram consideradas missing. Isso comprometeu parcialmente a capacidade do modelo para prever os casos de $\mathrm{y}=1$, isto é, os casos de uso regular da internet, como indica o teste de Hosmer e Lemeshow em nível crítico $(0,030)$, mas acima do patamar que recomendaria descartar o modelo $(0,010)$.
Os resultados para a Argentina (Quadro 4) têm mais semelhanças do que diferenças em comparação com o caso brasileiro. Idade, escolaridade, local de moradia e interesse por política tiveram significância em todos os modelos em que foram incluídos. No entanto, também mostraram influência consistente a renda e a ocupação, que não tiveram significância no caso brasileiro. Alguém que declarou estar nos degraus mais elevados da riqueza - portanto caracterizado aqui como tendo renda alta - tem 2,2 vezes a chance de uma pessoa que se vê nos degraus mais baixos. No caso da ocupação, o que fez diferença foi a condição de aposentado, donade-casa ou desempregado: argentinos definidos como não-PEA (fora da População Economicamente Ativa) têm menos chance de serem usuários de internet do que empregados manuais.

No quesito associativismo, são os sindicatos - mais do que as entidades esportivas e culturais - que favorecem a conexão à internet, eventualmente por disponibilizarem pontos de acesso aos associados. E, no que toca à mídia, tanto a exposição a jornais quanto a notícias no rádio foram determinantes com significância. Também no caso argentino houve elevada proporção de missings $(16,3 \%)$ no terceiro modelo.

QUADRO 4 - REGRESSÃO LOGÍSTICA -ARGENTINA - USO REGULAR DA INTERNET

\begin{tabular}{|c|c|c|c|c|c|c|}
\hline & \multicolumn{2}{|c|}{$\begin{array}{c}\text { Modelo } 1 \\
\text { (só sócio- } \\
\text { demográficas) }\end{array}$} & \multicolumn{2}{|c|}{$\begin{array}{c}\text { Modelo } 2 \\
\text { (com variáveis } \\
\text { políticas) }\end{array}$} & \multicolumn{2}{|c|}{$\begin{array}{l}\text { Modelo } 3 \\
\text { (com mídia } \\
\text { tradicional) }\end{array}$} \\
\hline & $\begin{array}{l}\text { Razẫo de } \\
\text { chance }\end{array}$ & $p$ & $\begin{array}{l}\text { Razẫo de } \\
\text { chance }\end{array}$ & $p$ & $\begin{array}{l}\text { Razẫo de } \\
\text { chance }\end{array}$ & $p$ \\
\hline \multicolumn{7}{|l|}{$\begin{array}{l}\text { Idade (ref.: de } 18 \text { a } 25 \\
\text { anos) }\end{array}$} \\
\hline De 26 a 35 & 0,483 & 0,004 & 0,452 & 0,002 & 0,445 & 0,003 \\
\hline De 36 a 45 & 0,411 & 0,001 & 0,340 & 0,000 & 0,324 & 0,000 \\
\hline De 46 a 55 & 0,255 & 0,000 & 0,188 & 0,000 & 0,148 & 0,000 \\
\hline Mais de 55 & 0,098 & 0,000 & 0,067 & $\mathbf{0 , 0 0 0}$ & 0,046 & $\mathbf{0 , 0 0 0}$ \\
\hline Mulher & 0,998 & 0,990 & 1,210 & 0,297 & 1,417 & 0,077 \\
\hline \multicolumn{7}{|l|}{$\begin{array}{l}\text { Escolaridade (ref.: } 1^{\text {arb }} \\
\text { inc.) }\end{array}$} \\
\hline $1^{\text {arb }}$ completo & 0,570 & 0,230 & 0,545 & 0,203 & 0,560 & 0,255 \\
\hline $2^{\text {ab }}$ inc ompleto & 2,721 & 0,017 & 2,212 & 0,063 & 2,243 & 0,077 \\
\hline $2^{\mathrm{arb}}$ completo & 4,745 & 0,000 & 4,006 & 0,001 & 4,079 & 0,002 \\
\hline Sup. incompleto ou mais & 17,803 & 0,000 & 13,195 & 0,000 & 10,956 & 0,000 \\
\hline
\end{tabular}




\begin{tabular}{|c|c|c|c|c|c|c|}
\hline \multicolumn{7}{|l|}{ Renda (ref.: baixa) } \\
\hline Média & 1,799 & 0,006 & 1,820 & 0,007 & 2,011 & 0,004 \\
\hline Alta & 2,249 & 0,000 & 2,138 & 0,001 & 2,131 & 0,002 \\
\hline \multicolumn{7}{|l|}{ Ocupação (ref.: manuais) } \\
\hline $\begin{array}{l}\text { Donos, liberais e } \\
\text { gerenciais }\end{array}$ & 1,349 & 0,218 & 1,342 & 0,237 & 1,298 & 0,322 \\
\hline Estudantes & 1,676 & 0,234 & 1,802 & 0,176 & 1,851 & 0,162 \\
\hline Nẫo-PEA & 0,419 & $\mathbf{0 , 0 0 0}$ & 0,437 & 0,000 & 0,420 & 0,000 \\
\hline \multicolumn{7}{|l|}{$\begin{array}{l}\text { Etnia (ref. indígenal } \\
\text { mestiç o) }\end{array}$} \\
\hline Branco & 1,317 & 0,176 & 1,326 & 0,175 & 1,258 & 0,300 \\
\hline $\begin{array}{l}\text { Outros (inclui } \\
\text { negrómulato) }\end{array}$ & 1,278 & 0,529 & 1,095 & 0,822 & 1,044 & 0,922 \\
\hline & & & & & & \\
\hline \multicolumn{7}{|l|}{$\begin{array}{l}\text { Cidade (ref.: até } 20 \text { mil } \\
\text { habitantes) }\end{array}$} \\
\hline Mais de 20 mil a $100 \mathrm{mil}$ & 1,232 & 0,504 & 1,173 & 0,619 & 1,196 & 0,591 \\
\hline Mais de $100 \mathrm{mil}$ & 2,426 & $\mathbf{0 , 0 0 1}$ & 2,679 & $\mathbf{0 , 0 0 0}$ & 2,507 & 0,001 \\
\hline Interesse por política & & & 1,684 & 0,006 & 1,633 & 0,015 \\
\hline \multicolumn{7}{|l|}{ Associativismo } \\
\hline Partido & & & 1,353 & 0,200 & 1,434 & 0,145 \\
\hline Sindicato & & & 1,957 & 0,016 & 2,152 & 0,010 \\
\hline Igreja & & & 0,957 & 0,822 & 0,941 & 0,765 \\
\hline $\begin{array}{l}\text { Grupo } \\
\text { esportivolazericultural }\end{array}$ & & & 1,411 & 0,074 & 1,504 & 0,044 \\
\hline \multicolumn{7}{|l|}{$\begin{array}{l}\text { Mídia (5 ou + } \\
\text { vezesisemana) }\end{array}$} \\
\hline \multirow{3}{*}{\multicolumn{5}{|c|}{$\begin{array}{l}\text { Vê notícias na TV } \\
\text { Lê jornal } \\
\text { Ouve notícias no rádio }\end{array}$}} & 0,715 & 0,093 \\
\hline & & & & & 2,190 & 0,002 \\
\hline & & & & & 1,542 & 0,022 \\
\hline Constante & 0,213 & 0,002 & 0,168 & 0,000 & 0,156 & 0,001 \\
\hline \multirow[t]{2}{*}{$\mathbf{N}$} & & 1. 107 & & 1. 101 & & 1.004 \\
\hline & $\begin{array}{c}\mathbf{r}^{2} \\
\text { Negelker } \\
\mathbf{k} \\
\mathbf{0 , 5 3 4}\end{array}$ & $\begin{array}{c}\text { Teste } \\
\text { H\&L } \\
0,389\end{array}$ & $\begin{array}{c}\mathbf{r}^{2} \\
\text { Negelker } \\
\mathbf{k} \\
\mathbf{0 , 5 5 5}\end{array}$ & $\begin{array}{c}\text { Teste } \\
\text { H\&L } \\
\mathbf{0 , 2 3 3}\end{array}$ & $\begin{array}{c}\mathbf{r}^{2} \\
\text { Negelker } \\
\mathbf{k} \\
0,573\end{array}$ & $\begin{array}{c}\text { Teste } \\
\text { H\&L } \\
0,294\end{array}$ \\
\hline
\end{tabular}

FONTE: Latinobarómetro (2007)

NOTA: Negrito destaca significância até $p<=0,05$. 
QUADRO 5 - REGRESSÃO LOGÍSTICA - CHILE - USO REGULAR DA INTERNET

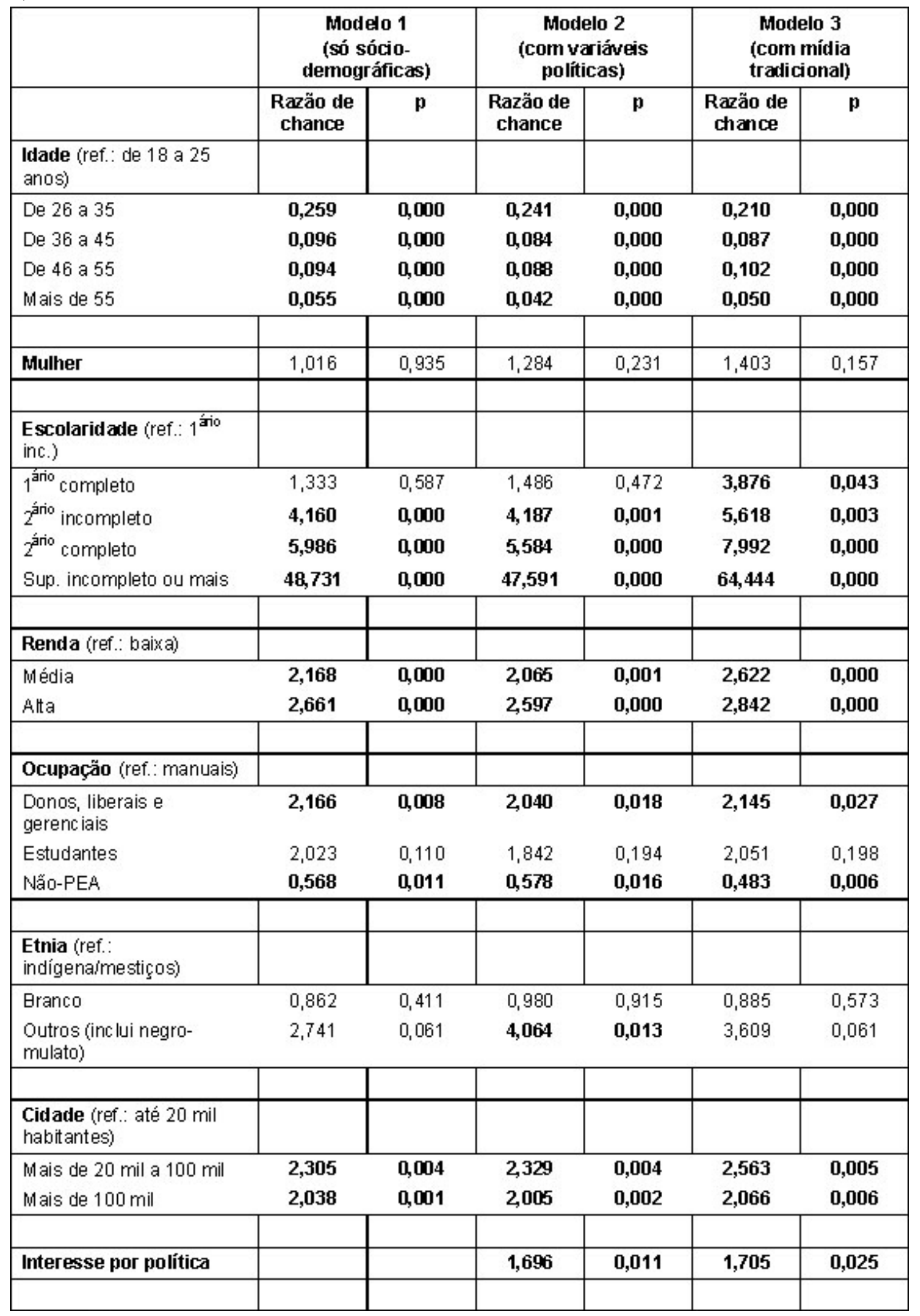




\begin{tabular}{|c|c|c|c|c|c|c|}
\hline \multicolumn{7}{|l|}{ Associativismo } \\
\hline Partido & & & 1,639 & 0,122 & 1,536 & 0,216 \\
\hline Sindicato & & & 1,123 & 0,685 & 0,901 & 0,742 \\
\hline Igreja & & & 0,962 & 0,854 & 1,034 & 0,893 \\
\hline $\begin{array}{l}\text { Grupo } \\
\text { esportivolazericultural }\end{array}$ & & & 1,537 & 0,053 & 1,780 & 0,021 \\
\hline \multicolumn{7}{|l|}{$\begin{array}{l}\text { Mídia (5 ou + } \\
\text { vezesisemana) }\end{array}$} \\
\hline Vê notícias na TV & & & & & 0,862 & 0,540 \\
\hline Lê jornal & & & & & 1,336 & 0,304 \\
\hline Ouve notícias no rádio & & & & & 1,044 & 0,842 \\
\hline Constante & 0,220 & 0,002 & 0,152 & 0,000 & 0,085 & 0,000 \\
\hline \multirow[t]{2}{*}{$\mathbf{N}$} & & 1.105 & & 1.078 & & 843 \\
\hline & $\begin{array}{c}\mathbf{r}^{2} \\
\text { Negelker } \\
\mathbf{k} \\
\mathbf{0 , 5 6 4}\end{array}$ & $\begin{array}{l}\text { Teste } \\
\text { H\&d } \\
0,330\end{array}$ & $\begin{array}{c}r^{2} \\
\text { Neggeaker } \\
\mathbf{k} \\
0,582\end{array}$ & $\begin{array}{c}\text { Teste } \\
\text { H\&L } \\
0,544\end{array}$ & $\begin{array}{c}r^{2} \\
\begin{array}{c}\text { Negelker } \\
\text { ke }\end{array} \\
\mathbf{0 , 5 8 3}\end{array}$ & $\begin{array}{c}\text { Teste } \\
\text { H\&L } \\
0,542\end{array}$ \\
\hline
\end{tabular}

Nos modelos para o Chile (Quadro 5), mais uma vez renda e ocupação aparecem como variáveis cruciais para determinar o acesso à internet. Com uma novidade: as condições de proprietário, profissional liberal ou funcionário gerencial favoreceram a conexão se comparadas à do assalariado manual; a de não-PEA desfavoreceu. Arredondando os números, o proprietário de um negócio no Chile tem duas vezes mais chances de estar conectado à internet do que um funcionário seu que faça um trabalho manual; e um desempregado tem metade da chance desse funcionário manual de ter acesso regular à rede mundial digital.

Idade, escolaridade, porte da cidade de moradia e interesse por política de novo tiveram significância em todos os modelos. Usos da mídia tradicional não se mostraram determinantes no terceiro modelo (que teve $29,8 \%$ dos casos dados como missing).

O modelo 2, do Chile, foi o único em que uma variável relacionada à cor da pele indicou fazer diferença. As variáveis relativas à etnia foram codificadas de maneira diversa, conforme o país. No Brasil, a categoria de referência é a de negros, mulatos e mestiços (mestiço foi entendido como filho do negro com o branco); a categoria "outros" inclui indígenas, orientais e indivíduos que também não se classificaram como brancos. Nos outros dois países, a categoria de referência é a de indígenas e mestiços (e mestiço foi entendido como filho do indígena com o branco); a categoria "outros" engloba negros, mulatos e pessoas que se classificaram de forma diferente das anteriores.

\section{III.2. Participação tradicional}

No passo seguinte, foi utilizada a análise de médias para verificar se os internautas dos três países diferenciam-se do restante da população em termos de participação tradicional. A internet dará voz a quem já tem meios e disposição de participar pelos canais tradicionais? Nesse ponto do estudo, a idéia é comparar os dois públicos sem o controle de outras variáveis sócio-demográficas ou políticas. Dessa forma, os resultados espelharão diferenças que podem ser entendidas não como geradas independentemente pelo uso da internet, mas também como fruto da própria condição social e demográfica dos usuários ${ }^{12}$.

12 A abordagem pode ser considerada adequada levandose em conta que o objetivo é mais cotejar a comunidade online com o restante da população do que verificar onde se originam eventuais diferenças de perfil - hipótese em que regressões multivariadas seriam mais indicadas. Com o procedimento estatístico adotado, não há controle de outras 
Como se verifica nas quadros 6 a 8 , tanto no Brasil quanto na Argentina e no Chile o usuário da internet apresenta-se como um tipo de cidadão mais participativo do que o restante da população. Questionado sobre as três formas de participação contempladas no questionário do Latinobarómetro, o grupo que usa regularmente a internet respondeu mais positivamente a cada um dos quesitos do que os não-usuários. E as diferenças demonstraram significância estatística, ressaltada em negrito, o que permite rejeitar a presunção de que, na população, as médias entre os dois grupos seriam iguais.

QUADRO 6 - COMPARAÇÃO DE MÉDIAS - BRASIL - USO REGULAR DA INTERNET X PARTICIPAÇÃO

\begin{tabular}{|l|c|c|c|}
\hline & $\begin{array}{c}\text { Usa a internet } \\
\text { regularmente } \\
\text { (i) }\end{array}$ & $\begin{array}{c}\text { Nunca usou ou } \\
\text { quase nunca } \\
\text { (ii) }\end{array}$ & $\begin{array}{c}\text { Diferença } \\
\text { (i }- \text { ii) } \\
\text { (com teste t) }\end{array}$ \\
\hline Assinou abaixo-assinado & $\mathbf{0 , 1 2 2}$ & $\mathbf{0 , 0 6 9}$ & $+\mathbf{0 , 0 5 3 ^ { 1 }}$ \\
Tomou parte em manifestaçẫo autorizada & $\mathbf{0 , 2 0 8}$ & $\mathbf{0 , 1 2 3}$ & $+\mathbf{0 , 0 8 4 ^ { 2 }}$ \\
Fez protesto sem autorizaçẫo & $\mathbf{0 , 1 8 3}$ & $\mathbf{0 , 0 8 1}$ & $\mathbf{+ 0 , 1 0 2 ^ { 2 }}$ \\
\hline
\end{tabular}

FONTE: Latinobarómetro (2007).

NOTAS: 1 . Significância até $p<=0,05$.

2. Significância até $p<=0,001$.

QUADRO 7 - COMPARAÇÃO DE MÉDIAS -ARGENTINA - USO REGULAR DA INTERNET X PARTICIPAÇÃO

\begin{tabular}{|l|c|c|c|}
\hline & $\begin{array}{c}\text { Usa a internet } \\
\text { regularmente } \\
\text { (i) }\end{array}$ & $\begin{array}{c}\text { Nunca usou ou } \\
\text { quase nunca } \\
\text { (ii) }\end{array}$ & $\begin{array}{c}\text { Diferença } \\
\text { (i- ii) } \\
\text { (com teste t) }\end{array}$ \\
\hline Assinou abaixo-assinado & $\mathbf{0 , 3 6 0}$ & $\mathbf{0 , 2 0 1}$ & $\mathbf{+ 0 , 1 5 9 ^ { 1 }}$ \\
Tomou parte em manifestaçẫo autorizada & $\mathbf{0 , 2 6 8}$ & $\mathbf{0 , 1 1 5}$ & $\mathbf{+ 0 , 1 5 3 ^ { 1 }}$ \\
Fez protesto sem autorizaçẫo & $\mathbf{0 , 1 7 0}$ & $\mathbf{0 , 0 5 1}$ & $\mathbf{+ 0 , 1 1 8}{ }^{1}$ \\
\hline
\end{tabular}

FONTE: Latinobarómetro (2007).

NOTA: 1 . Significância até $p<=0,001$.

QUADRO 8 - COMPARAÇÃO DE MÉDIAS - CHILE - USO REGULAR DAINTERNET X PARTICIPAÇÃO

\begin{tabular}{|l|c|c|c|}
\hline & $\begin{array}{c}\text { Usa a intemet } \\
\text { regularmente } \\
\text { (i) }\end{array}$ & $\begin{array}{c}\text { Nunca usou ou } \\
\text { quase nunca } \\
\text { (ii) }\end{array}$ & $\begin{array}{c}\text { Diferença } \\
\text { (i - ii) } \\
\text { (com teste t) }\end{array}$ \\
\hline Assinou abaixo-assinado & $\mathbf{0 , 1 8 3}$ & $\mathbf{0 , 0 8 5 2}$ & $+\mathbf{0 , 0 9 8}$ \\
Tomou parte em manifestaçẫo autorizada & $\mathbf{0 , 1 5 3}$ & $\mathbf{0 , 0 6 2 5}$ & $+\mathbf{0 , 0 9 0 ^ { 1 }}$ \\
Fez protesto sem autorizaçẫo & $\mathbf{0 , 0 9 4}$ & $\mathbf{0 , 0 2 9 2}$ & $+\mathbf{0 , 0 6 5 ^ { 1 }}$ \\
\hline
\end{tabular}

FONTE: Latinobarómetro (2007).

NOTA: 1 . Significância até $p<=0,001$.

variáveis: se os mais ricos ou mais escolarizados estão desproporcionalmente representados no mundo virtual, a análise possibilitará que o efeito disso expresse-se. O teste t, de diferença de médias, sinaliza se é possível inferir que as diferenças das médias da amostra reproduzem-se no universo geral da população. Diferenças de médias sem significância estatística podem indicar gradientes gerados aleatoriamente, sem que a população apresente de fato discrepância consistente; nesses casos, não se pode rejeitar a hipótese nula, de que os dois grupos comparados na verdade apresentam valores iguais para a variável observada. Uma vez que as variáveis utilizadas também nesta etapa são binárias, as médias que aparecem nos quadros abaixo resultam da proporção entre respostas negativas (0) e positivas (1) para cada um dos quesitos - por exemplo, média 0,300 é resultado de $30 \%$ de respostas positivas entre os entrevistados que pertencem a determinado grupo. Dessa forma, a segunda linha do Quadro 6 revela que $12,2 \%$ dos internautas brasileiros já assinaram abaixo-assinado, contra $6,9 \%$ dos não-conectados, e assim por diante. 


\section{III.3. Opiniões do internauta}

A última etapa da análise avaliou as eventuais diferenças de opinião entre a comunidade on-line e o restante da população. Em quesitos relevantes como a preferência pela democracia e o apoio à ação estatal, os internautas diferenciam-se em relação aos não-conectados? A escolha das atitudes observadas dependeu em grande medida da disponibilidade de questões no instrumento do
Latinobarómetro 2007. As perguntas encontradas permitiram avaliar as seguintes dimensões: apoio à democracia, confiança em instituições, atitude liberal ou estatizante em economia, proximidade com a Igreja, sensibilidade social e temor à criminalidade. Também nesses testes foi usado o teste de diferença de médias, como forma de deixar que diferenças no perfil sócio-demográfico de usuários e não-usuários expressassem-se.

QUADRO 9 -ANÁLISE DE MÉDIAS - BRASIL - USO REGULAR DA INTERNET XATITUDES

\begin{tabular}{|l|c|c|c|}
\hline & $\begin{array}{c}\text { Usa a internet } \\
\text { regularmente } \\
\text { (i) }\end{array}$ & $\begin{array}{c}\text { Não usa ou } \\
\text { quase nunca } \\
\text { (ii) }\end{array}$ & $\begin{array}{c}\text { Diferença } \\
\text { (i-ii) } \\
\text { (com teste t) }\end{array}$ \\
\hline Democracia é a melhor forma de governo & 0,535 & 0,487 & $+0,049$ \\
Confiança no governo & $\mathbf{0 , 3 0 9}$ & $\mathbf{0 , 3 7 1}$ & $-\mathbf{0 , 0 6 2}$ \\
Confiança no Congresso & $\mathbf{0 , 1 9 6}$ & $\mathbf{0 , 2 6 9}$ & $-\mathbf{0 , 0 7 2}$ \\
Confiança no Judiciário & 0,421 & 0,420 & $+0,001$ \\
Confiança nas Forças Armadas & 0,709 & 0,671 & $+0,038$ \\
Confiança em empresas privadas & $\mathbf{0 , 4 8 7}$ & $\mathbf{0 , 3 9 7}$ & $+\mathbf{0 , 0 9 1}$ \\
Estado deve resolver maioria dos problemas & 0,370 & 0,424 & $-0,054$ \\
As privatizaçốes foram benéficas para o país & 0,554 & 0,521 & $+0,033$ \\
Confiança na lgreja & $\mathbf{0 , 7 5 3}$ & $\mathbf{0 , 8 2 9}$ & $\mathbf{- 0 , 0 7 5}$ \\
Aborto nunc a é justificável & $\mathbf{0 , 5 5 2}$ & $\mathbf{0 , 6 5 1}$ & $\mathbf{- 0 , 0 9 9}$ \\
Distribuiçẫo de renda é muito injusta no país & $\mathbf{0 , 3 9 1}$ & $\mathbf{0 , 3 0 3}$ & $\mathbf{+ 0 , 0 8 9}$ \\
Medo de ser vítima de crime todo o tempo & 0,403 & 0,419 & $-0,016$ \\
\hline
\end{tabular}

FONTE: Latinobarómetro (2007).

NOTAS: 1 . Significância até $p<=0,05$.

2. Significância até $p<=0,001$.

3. "Democracia é a melhor forma de governo" expressa a escolha pela frase "A democracia é preferivel a qualquer outra forma de governo", em detrimento de "Em algumas circunstâncias, um governo autoritário pode ser preferível a um governo democrático" e "Para pessoas como eu, tanto faz se o governo é democrático ou não-democrático" (como nos demais casos, a média refere-se à proporção entre respostas 0 e 1); variáveis relativas à confiança em instituições expressam a opção por "muita confiança" ou "alguma confiança"; "Estado deve resolver a maioria dos problemas" expressa as respostas "a maioria" e "todos os problemas"; "As privatizações foram benéficas para o país" expressa muita ou alguma concordância com essa frase; "Aborto nunca é justificável" expressa localização no nível 1 em uma escala de tolerância que vai de 1 (nunca é justificável) a 10 (sempre justifica-se); "Distribuição de renda é muito injusta no país" expressa escolha pela gradação "muito injusta" em pergunta sobre o quanto é justa a distribuição de renda; "Medo de ser vítima de crime todo o tempo" expressa as respostas "todo o tempo" ou "quase todo o tempo", referente à pergunta sobre a freqüência com que o entrevistado sente-se ameaçado por um delito de violência.

Os resultados para o Brasil aparecem no Quadro 9: por aqui, o internauta confia menos no governo, no Congresso e na Igreja; confia mais nas empresas privadas; é mais sensível à desigualdade de renda e mais tolerante em relação ao aborto.
Nos outros seis quesitos não foram observadas diferenças consistentes nas atitudes dos dois segmentos do público. São resultados que, genericamente, sugerem um público de usuários de internet sem uma diferenciação de sentido claro em rela- 
ção aos não-usuários - embora essa conclusão mereça ressalvas, como será discutido na última seção do artigo.
No caso da Argentina (Quadro 10), os internautas são mais democratas e confiam menos no governo, na Igreja e nas Forças Armadas, e também são mais tolerantes com o aborto.

QUADRO 10 -ANÁLISE DE MÉDIAS - ARGENTINA - USO REGULAR DA INTERNET XATITUDES

\begin{tabular}{|l|c|c|c|}
\hline & $\begin{array}{c}\text { Usa a internet } \\
\text { regularmente } \\
\text { (i) }\end{array}$ & $\begin{array}{c}\text { Não usa ou } \\
\text { quase nunca } \\
\text { (ii) }\end{array}$ & $\begin{array}{c}\text { Diferença } \\
\text { (i-ii) } \\
\text { (com teste t) }\end{array}$ \\
\hline Democracia é melhor forma de governo & $\mathbf{0 , 7 3 8}$ & $\mathbf{0 , 5 8 1}$ & $\mathbf{+ 0 , 1 5 8 ^ { 2 }}$ \\
Confiança no governo & $\mathbf{0 , 3 0 9}$ & $\mathbf{0 , 3 7 9}$ & $\mathbf{- 0 , 0 7 1}$ \\
Confiança no Congresso & 0,216 & 0,258 & $-0,042$ \\
Confiança no Judiciário & 0,256 & 0,218 & $+0,038$ \\
Confiança nas Forças Armadas & $\mathbf{0 , 3 6 5}$ & $\mathbf{0 , 4 4 7}$ & $-\mathbf{0 , 0 8 2}$ \\
Confiança nas empresas privadas & 0,389 & 0,347 & $+0,042$ \\
Estado deve resolver maioria dos problemas & 0,474 & 0,470 & $+0,004$ \\
As privatizaçốes foram benéficas para o país & 0,218 & 0,187 & $+0,031$ \\
Confiança na lgreja & $\mathbf{0 , 5 9 3}$ & $\mathbf{0 , 6 7 1}$ & $-\mathbf{0 , 0 7 8}$ \\
Aborto nunca é justificável & $\mathbf{0 , 4 5 4}$ & $\mathbf{0 , 5 9 8}$ & $-\mathbf{0 , 1 4 4}$ \\
Distribuiçẫo de renda é muito injusta no país & 0,329 & 0,302 & $+0,027$ \\
Medo de ser vítima de crime todo o tempo & 0,369 & 0,368 & $-0,001$ \\
\hline
\end{tabular}

FONTE: Latinobarómetro (2007).

NOTAS: 1 . Significância até $p<=0,05$.

2. Significância até $p<=0,001$.

3. Idem nota número 3 do Quadro 9.

QUADRO 11 - ANÁLISE DE MÉDIAS - CHILE - USO REGULAR DA INTERNET X ATITUDES ${ }^{1}$

\begin{tabular}{|l|c|c|c|}
\hline & $\begin{array}{c}\text { Usa a internet } \\
\text { regularmente } \\
\text { (i) }\end{array}$ & $\begin{array}{c}\text { Não usa ou } \\
\text { quase nunca } \\
\text { (ii) }\end{array}$ & $\begin{array}{c}\text { Diferença } \\
\text { (i - ii) } \\
\text { (com teste t) }\end{array}$ \\
\hline Democracia é melhor forma de governo & 0,523 & 0,464 & $-0,060$ \\
Confiança no governo & 0,470 & 0,457 & $+0,013$ \\
Confiança no Congresso & $\mathbf{0 , 3 3 3}$ & $\mathbf{0 , 2 7 3}$ & $\mathbf{+ 0 , 0 6 0 ^ { 2 }}$ \\
Confiança no Judiciário & 0,241 & 0,207 & $+0,034$ \\
Confiança nas Forças Armadas & 0,646 & 0,638 & $+0,008$ \\
Confiança em empresas priv adas & $\mathbf{0 , 4 7 5}$ & $\mathbf{0 , 3 3 7}$ & $\mathbf{+ 0 , 1 3 8 ^ { 3 }}$ \\
Estado deve resolver maioria dos problemas & $\mathbf{0 , 3 6 9}$ & $\mathbf{0 , 4 2 7}$ & $\mathbf{- 0 , 0 6 8}$ \\
As privatizaçốes foram benéficas para o país & 0,417 & 0,361 & $+0,057$ \\
Confiança na lgreja & $\mathbf{0 , 6 5 8}$ & $\mathbf{0 , 7 3 0}$ & $\mathbf{- 0 , 0 7 2}$ \\
Aborto nunca é justificável & $\mathbf{0 , 5 6 3}$ & $\mathbf{0 , 7 4 7}$ & $\mathbf{- 0 , 1 9 5 ^ { 3 }}$ \\
Distribuiçẫo de renda é muito injusta no país & 0,434 & 0,458 & $-0,024$ \\
Medo de ser vítima de crime todo o tempo & 0,334 & 0,382 & $-0,048$ \\
\hline
\end{tabular}

FONTE: Latinobarómetro (2007).

NOTAS: 1. As alternativas de resposta e seus significados são os mesmos do quadro referente ao Brasil e à Argentina.

2. Significância até $p<=0,05$.

3. Significância até $p<=0,001$. 
Nos demais quesitos, conectados e nãoconectados não apresentaram diferença de atitudes com significância estatística. Para o Chile (Quadro 11), houve diferenciação dos internautas também em cinco quesitos, mas com orientação mais clara: foi detectada alguma inclinação liberal, a partir de diferenças significativas nos quesitos sobre intervenção estatal e confiança em empresas privadas. Como no caso brasileiro, também apareceu uma inclinação secular, expressa pela maior desconfiança na Igreja e pela maior tolerância com o aborto.

\section{CONCLUSÕES}

De forma geral, as evidências levantadas neste estudo sugerem que, no contexto brasileiro atual, a internet tende a dar voz a setores que já têm mais condições de fazer chegar seus inputs aos operadores do sistema político e formuladores de políticas públicas. Mas há sinais de oportunidades para a ampliação da participação de outros segmentos sociais, cujo deficit de poder no mundo pré-digital não se traduziu em maior dificuldade de acesso à internet. E a importância do "digital divide" deve ser relativizada por conta da menor diferenciação de opiniões entre quem está e quem não está conectado.

Para analisar em mais detalhes, voltemos às proposições utilizadas como hipóteses. A hipótese 1 apontava escolaridade, renda e ocupação como determinantes, de forma independente, do uso regular da internet. Trata-se de indicadores promissores da posição de centralidade na sociedade e na política. Ela foi confirmada apenas parcialmente, pois a escolaridade demonstrou forte impacto na chance de acesso, mas a ocupação e uma proxy de renda não apresentaram influência, o que também ocorreu com a etnia e o gênero - todas características sócio-demográficas recorrentemente apontadas como decisivas para a inclusão ou exclusão digital. A comparação com a Argentina e o Chile aqui se revelou especialmente útil. Em ambos os países, ocupação e proxy de renda foram capazes de influenciar a chance de acesso regular ao universo digital.

Esse resultado é um indício de que o chamado "digital divide" pode ter características próprias no Brasil, que por sua vez demandam uma pesquisa mais aprofundada e eventuais ações de combate específicas. $\mathrm{O}$ fato de a escolaridade aparecer com tanta força como determinante do aces- so à internet pode indicar que o combate à exclusão digital no Brasil deve passar pela inclusão educacional, com ampliação do acesso à escola de qualidade. Naturalmente, a escolaridade é ela própria um indicador de posição social, refletindo a renda e a centralidade nas redes sociais e no sistema político (BORDIEU \& PASSERON, 1990; NIE, JUNN \& STEHLIK-BARRY， 1996; MENEZES-FILHO, 2008). São conhecidos os trabalhos acadêmicos que mostram a heterogeneidade na escolaridade da força de trabalho como o principal determinante do nível geral de desigualdade salarial observada no Brasil, a exemplo de Neri (2000) e Barros, Henriques \& Mendonça (2000). Mas um olhar mais amplo para os resultados sugere a preponderância do que se pode chamar de capital cultural - basicamente informação e conhecimento - como determinante do uso regular da internet. A julgar pelas variáveis com significância nos modelos de regressão para o Brasil - idade, escolaridade, tamanho da cidade de moradia, interesse por política, participação em associação esportiva ou cultural e leitura intensiva de jornais - a inclusão digital passa pela inclusão cultural mais do que por iniciativas voltadas ao mundo do trabalho. A constatação de que a ocupação não diferencia o brasileiro em termos de conexão à rede digital aponta para a menor necessidade de ações voltadas exclusivamente ao mercado de mão-de-obra. Tendência semelhante ocorre no caso da cor da pele: o fato de não ser decisiva para o uso regular pode indicar, de um lado, sucesso das iniciativas públicas ou privadas de equalização do acesso e, de outro, que ações afirmativas com esse foco correm o risco de não ser a melhor opção de aplicação de energia e recursos com vistas à democratização das novas tecnologias.

Os achados também recomendam que a discussão dos impactos políticos da internet não se deixe aprisionar pela visão de um dilema sem solução entre a interpretação de que a nova tecnologia apenas reforça a voz dos que já têm voz e, pelo outro lado, a de que promoverá uma mobilização espetacular de novos participantes. Junto de sinais de que o acesso à internet em grande medida reproduz o poder de expressão dos que têm mais conhecimento e informação, apareceram as possibilidades de participação ampliada de segmentos diferenciados - sobretudo os mais jovens. Estudos internacionais consistentemente demonstram que os mais jovens engajam-se na política em ní- 
vel muito menor do que os mais velhos; eles têm menor probabilidade de mostrar interesse no assunto, votar, participar de atividades não-eleitorais e engajar-se em esforços de mobilização (VERBA, SCHLOZMAN \& BRADY, 1995; DELLI CARPINI, 2000; PUTNAM, 2000). A maior presença jovem na internet, um meio que diminui os custos de informar-se e de participar, é um dado promissor - embora estudos recentes recomendem cautela, por constatarem que a baixa motivação dos jovens para a política reproduz-se nos meios digitais (LIVINGSTONE, COLDRY \& MARKHAM, 2007).

A hipótese 2 foi confirmada, pois o internauta brasileiro apresentou níveis de participação tradicional mais elevados do que o restante da população. Isso serve de indício adicional de que são aqueles que já têm perfil mais atuante na política off-line que terão voz no mundo político virtual. Naturalmente, isso não é o mesmo que verificar as condições em que a participação on-line acontece ou acontecerá, pois ela está sujeita a dinâmicas e condicionantes próprios. Os que estão conectados são mais os participativos, mas a partir daí não se pode inferir diretamente que a participação on-line será dominada por essas mesmas pessoas. Trata-se, antes, de um sinal de alerta: se as tecnologias digitais reduzem os custos de participação e eventualmente aumentam a motivação, são os setores mais ativados da sociedade brasileira que hoje têm mais condições de tirar proveito dessas possibilidades. Além disso, se a participação via internet contribuir "apenas" para reproduzir as desigualdades já constatadas nos meios tradicionais, reproduzindo a política usual (MARGOLIS \& RESNIK, 2000), estará em risco uma das fontes de seu potencial para fortalecer a democracia.

Mais otimismo pode gerar o teste da hipótese 3 , pois o internauta brasileiro não apresenta valores diferenciados do restante da população de forma marcante. Como o uso regular da internet privilegia estratos sociais mais integrados culturalmente, o prejuízo potencial para o tratamento igualitário das preferências de todos os cidadãos será tanto maior quanto maior a distância entre as opiniões de incluídos e excluídos digitais. De forma geral, não houve divergências com um sentido claro e consistente entre conectados e nãoconectados, contrariando os achados de Best e Krueger (2005) para os Estados Unidos e de Norris (2001) a partir do Eurobarômetro de 1999.
No caso brasileiro, porém, há ressalvas relevantes: o internauta mostrou-se mais crítico em relação a duas instituições centrais para o funcionamento democrático - governo e Congresso. É um sinal oposto ao que costuma ser encontrado em estudos sobre países desenvolvidos. Criadas para assegurar a distribuição de poder na sociedade e também para possibilitar aos cidadãos avaliarem e julgarem o desempenho dos que governam em seu nome, a desvalorização pública dessas instituições pode levar ao seu esvaziamento (MOISÉS, 2007). Por outro lado, a desconfiança nessas instituições pode ganhar novos contornos quando cotejada com outros achados do estudo. Também a confiança na Igreja é menor entre os internautas, ao mesmo tempo em que é maior a tolerância ao aborto. No conjunto, esses traços poderiam indicar a emergência de valores pósmaterialistas, como definidos por Inglehart (2002): ênfase na sociabilidade, na auto-expressão, na qualidade de vida, na participação e na autoridade não-hierárquica, com conseqüente declínio do apego à religião e às instituições democráticas tradicionais. Um trabalho anterior publicado neste periódico (RIBEIRO, 2007) desaconselha essa linha de inferência por não detectar traços pósmaterialistas em públicos brasileiros mais jovens, e serve como mais um sinal da necessidade de investigação mais detalhada para compreender essas evidências.

Por fim, os dados da Argentina e do Chile tiveram sinal contrário à tese da normalização, trabalhada na hipótese 4 e entendida como inclusão crescente dos diversos setores sociais até o limite em que todos estariam representados no mundo digital. A maior proporção de cidadãos conectados não significou equalização de oportunidades de uso regular. Idade, escolaridade, proxy de renda, ocupação, porte da cidade de moradia, interesse por política e, no caso argentino, uso intensivo da mídia tradicional, foram variáveis que diferenciaram o cidadão em termos de inclusão digital. Os valores do $r^{2}$ de Negelkerke, que serve de indicador sobre quanto da variação da dimensão de interesse foi explicado pelo modelo de regressão logística, estiveram próximos dos encontrados para o Brasil, na faixa de 55\%. Isso significa que o cabedal do indivíduo em termos socioeconômicos e demográficos continua sendo decisivo como determinante para o acesso também nesses dois países. As evidências levantadas neste estudo não podem ser tomadas como capazes de refutar a 
tese da normalização, mas indicam que, se ela pode ocorrer, ainda está distante nos países latino-americanos observados.

No que toca a atitudes, manteve-se nos dois países a tendência de pouca diferenciação entre conectados e não-conectados, com raras divergências consistentes. $\mathrm{O}$ internauta argentino apresentou perfil mais próximo do cidadão crítico, descrito por Norris (1999): alguém que preza a democracia, mas avalia com severidade as instituições. No caso chileno, foi o perfil liberal em economia o traço que mais se destacou, acompanhando os resultados de Best e Krueger (2005).

Novos estudos são necessários para aprofundar as questões apenas arranhadas neste trabalho, sobretudo com objetivos mais específicos, a partir de bases de dados mais amplas e com desenhos de pesquisa mais focados. Este artigo terá atingido seus objetivos se conseguir ao menos realçar a relevância de abordagens que dêem centralidade ao usuário na pesquisa sobre o impacto das novas tecnologias no país.

Rogerio Schlegel (rschlegel@usp.br) é Doutorando em Ciência Política pela Universidade de São Paulo e bolsista da Capes (Coordenação de Aperfeiçoamento de Pessoal de Nível Superior).

\section{REFERÊNCIAS BIBLIOGRÁFICAS}

BARBER, B. R. 1998. Three Scenarios for the Future of Technology and Strong Democracy. Political Science Quarterly, v. 113, n. 4, p. 573-589, Winter.

2004. Strong Democracy : Participatory Politics for a New Age. Berkeley : University of California.

BARROS, R. P.; HENRIQUES, R. \& MENDONÇA, R. 2000. Pelo fim das décadas perdidas : educação e desenvolvimento sustentado no Brasil. In : HENRIQUES, R. (org.). Desigualdade e pobreza no Brasil. Rio de Janeiro : IPEA, p. 405-423. Disponível em : http:// www.ipea.gov.br/sites/000/2/livros/ desigualdadepobrezabrasil/capitulo14.pdf Acesso em : 13.jul.2009. Também disponível em : www.ipea.gov.br/pub/td/2002/ td_0857.pdf Acesso em : 13.jul.2009.

BEST, S. J. \& KRUEGER, B. 2005. Analyzing the Representativeness of Internet Political Participation. Political Behavior, v. 27, n. 2, p. 183-216, June.

BIMBER, B. 2000. The Study of Information Technology and Civic Engagement. Political Communication, v. 17, n. 4, p. 329-333, Jan.

BOURDIEU, P. \& PASSERON, J-C. 1990. Reproduction in Education, Society and Culture. London : Sage.

BRAGA, S. S. 2007. Podem as novas tecnologias de informação e comunicação auxiliar na consolidação das democracias? Um estudo sobre a informatização dos órgãos legislativos na América do Sul. Opinião Pública, Campinas, v. 13, n. 1, p. 1-50. Disponível em : www.scielo.br/pdf/op/v13n1/v13n1a01.pdf Acesso em : 13.jul.2009.

CHAIA, V. 2006. As novas formas de participação política e as comunidades on-line : um estudo do Orkut. In : CONGRESSO LATINOAMERICANO DE CIÊNCIA POLÍTICA, 3. Campinas. Anais... Campinas : UNICAMP.

COLE, J. I.; SUMAN, M.; SCHRAMM, P. ; LUNN, R. \& AQUINO, J-S. 2003. The UCLA Internet Report: Surveying the Digital Future - Year Three. Los Angeles : UCLA Center for Communication Policy. Disponível em : http:/ /images.forbes.com/fdc/mediaresourcecenter/ UCLA03.pdf Acesso em : 13.jun.2009.

CONVERSE, P. E. 2006. The Nature of Belief Systems in Mass Publics. In : APTER, D. E. (org.). Ideology and Discontent. New York : The Free Press.

CORGOZINHO, I. 2003. A democracia eletrônica em Minas Gerais. Fronteira Virtual, n. 8. Disponível em : http://www.sglweb.com.br/ sgl-mkt/artigo.htm Acesso em : 25.jan.2009.

DAHL, R. 1989. Democracy and its Critics. New Haven : Yale University.

DELLI CARPINI, M. X. 2000. Gen.com : Youth, Civic Engagement, and the New Information Environment. Political Communication, n. 17, p. 341-349. Disponível em : http:// 
ccce.com.washington.edu/news/assets/ conference_papers/carpini.pdf. Acesso em : 13.jul.2009.

DELLI CARPINI, M. X. \& KEETER, S. 1997. What Americans Know About Politics and Why It Matters. Yale : Yale University.

DOWNS, A. 1999. Uma teoria econômica da democracia. São Paulo : EDUSP.

HABERMAS, J. 2003. Mudança Estrutural da Esfera Pública : Investigações quanto a uma Categoria da Sociedade Burguesa. Rio de Janeiro : Tempo Brasileiro.

HOSMER, D. W. \& LEMESHOW, S. 2000. Applied Logistic Regression. New York : Wiley-Interscience.

IASULAITIS, S. 2006. A internet pode revigorar as eleições? Um estudo das campanhas virtuais presidenciais do pleito de 2006. In : ENCONTRO ANUAL DA ANPOCS, 31., Caxambu. Anais... Caxambu : ANPOCS.

INGLEHART, R. 2002. Cultura e Democracia. In : HARRINSON, L. E. \& HUNTINGTON, S. A cultura importa. Rio de Janeiro : Record.

KIESLER, S.; ZDANIUK, B.; LUNDMARK, V. \& KRAUT, R. 2000. Troubles With the Internet : the Dynamics of Help at Home. Human-Computer Interaction, v. 15, p. 323351. Disponível em : http:// homenet.hcii.cs.cmu.edu/progress/Kiesler00TeenGuru.pdf Acesso em : 13.jul.2009.

KLING, R. 1999. What is Social Informatics and Why Does it Matter? D-Lib Magazine, v. 5, n. 1, Jan., p. 1-30. Disponível em : http:// www.dlib.org/dlib/january 99/kling/ 01kling.html Acesso em : 13.jul.2009.

JOHNSON, T. J. \& KAYE, B. K. 2003. A Boost or Bust for Democracy? How the Web Influenced Political Attitudes and Behaviors in the 1996 and 2000 Presidential Elections. Harvard International Journal of Press/ Politics, v. 8, n. 3, p. 9-34.

LATORRE, M. 2004. Medidas de Risco e Regressão Logística. In : MASSAD, E.; MENEZES, R. X.; SILVEIRA, P. S-P. \& ORTEGA, N. R. S. (orgs.). Métodos Quantitativos em Medicina. São Paulo : Manole.
LEVY, S. 2004. Dean's Net Effect is Just the Start. Newsweek, n. 143, 29.Mar, p. 73.

LIJPHART, A. 1997. Unequal Participation : Democracy's Unresolved Dilemma. American Political Science Review, v. 91, n. 1 p. 1-14, Mar. Disponível em : http:// c s a 11 e n.m y w e b. u ga . e d u / lijphart_unequal_apsr_1997.pdf. Acesso em : 13.jul.2009.

LIVINGSTONE，S.; COULDRY，N. \& MARKHAM, T. 2007. Youthful Steps Towards Civic Participation : Does the Internet Help? In : LOADER, B. D. Young Citizens in the Digital Age : Political Engagement, Young People and New Media. Abingdon : Routledge.

LLOYD, R. \& BILL, A. 2004. Australia On-line : How Australians are Using Computers and the Internet 2001. Canberra : Australian Bureau of Statistics, Australian Census Analytic Program, Publication 2056.0. Disponível em : http://www.abs.gov.au/AUSSTATS/abs@.nsf/ DetailsPage/2056.02001?OpenDocument Acesso em : 13.jun.2009.

MARGOLIS, M. \& RESNICK, D. 2000. Politics as Usual : the Cyberspace "Revolution". Thousand Oaks, CA. : Sage.

MENEZES-FILHO, N. 2008. Os determinantes do desempenho escolar no Brasil. São Paulo : Instituto Futuro Brasil-Ibmec-USP. Disponível em : http://ibmecsp.edu.br/pesquisa/ download.php?recid=3447 Acesso em : 13.jul.2009.

MOISÉS, J. A. 2007. Democracy, Trust and Democratic Institutions in Brazil. In : IPSA WORLD CONGRESS, 20, FUKUOKA. Anais... Fukuoka : IPSA, July, versão revisada.

NERI, N. 2000. Políticas estruturais de combate à pobreza no Brasil. In : HENRIQUES, R. (coord.). Desigualdade e pobreza no Brasil. Rio de Janeiro : IPEA.

NEUMAN, R. 1986. The Paradox of Mass Politics : Knowledge and Opinion in the American Electorate. Cambridge : Harvard University.

NIE, N. H.; JUNN, J. \& STEHLIK-BARRY, K. 1996. Education and Democratic Citizenship in America. Chicago : University of Chicago. 
NORRIS, P. 1999. The Growth of Critical Citizens? In: . Critical Citizens : Global Support for Democratic Government. Oxford : Oxford University.

2001. The Digital Divide. Cambridge : Cambridge University.

PAGE, B. \& SHAPIRO, R. 1992. The Rational Public : Fifty Years of Trends in American's Policy Preferences. Chicago : University of Chicago.

PERES，C. A.; OLIVEIRA， M. C. \& ANOROZO, N. F. 2008. Relatório de análise estatística sobre o projeto: "Escolaridade e inclusão política”. São Paulo : IME-USP.

PUTNAM, R. 2000. Bowling Alone: The Collapse and Revival of American Community. New York : Simon \& Schuster.

RIBEIRO, E. A. 2007. Cultura política, instituições e experiência democrática no Brasil. Revista de Sociologia e Política, Curitiba, n. 28, jun. Disponível em : http://www.scielo.br/pdf/ rsocp/n28/a13n28.pdf Acesso em : 13.jul.2009.

SCHUMPETER, J. A. 1984. Capitalismo, Socialismo e Democracia. São Paulo : J. Zahar.

SILVA, S. P. 2005. Graus de participação democrática no uso da internet pelos governos das capitais brasileiras. Opinião Pública, Campinas, v. 11, n. 2, p. 450-468, out. Disponível em : http://www.gepicc.ufba.br/enlepicc/pdf/ SivaldoPereira.pdf Acesso em 13.jul.2009.

VERBA, S.; SCHLOZMAN, K. \& BRADY, H. E. 1995. Voice and Equality. Cambridge, MA. : Harvard University.

WLEZIEN, C. \& SOROKA, S. N. 2007. The Relationship Between Public Opinion and Policy. In: DALTON, R. J. \& KLINGEMANN, H-D. The Oxford Handbook of Political Behavior. Oxford : Oxford University.

\section{OUTRAS FONTES}

IBOPE \& NETRATINGS. 2008. Indicadores mensais e trimestrais. Perfil do internauta e atividades realizadas, terceiro trimestre de 2008. Disponível em : http://www.cetic.br/usuarios/ ibope/index.htm Acesso em : 16.jul.2009.

INTERNET WORLD STATS. 2009. Sitio de internet do banco de estatísticas de uso da internet Internet World Stats. Disponível em : http://www.internetworldstats.com/ Acesso em : 16.jul.2009.

LATINOBARÓMETRO. 2007. Sítio de internet do instituto Latinobarómetro. Survey do ano de 2007. Disponível em : http:// www.latinobarometro.org/ Acesso em : 16.jul.2009.

NTIA. 1999. Falling Through the Net : Defining the Digital Divide. Washington, D. C. : U.S. Department of Commerce. Disponível em : http://www.ntia.doc.gov/ntiahome/fttn99/ Acesso em : 16.jul.2009.

OECD. 2000. Information technology Outlook. Paris : OECD. Disponível em : http:// www.oecd.org/dataoecd/30/56/1939833.pdf Acesso em : 16.jul.2009. Também disponível em : http://www.oecd.org/document/20/ 0,3343,en_2649_33757_41892820_1_1_1_1,00.html Acesso em : 16.jul.2009. 